\title{
IUCrJ
}

Volume 3 (2016)

Supporting information for article:

The crystalline sponge method updated

Manabu Hoshino, Anupam Khutia, Hongzhu Xing, Yasuhide Inokuma and Makoto Fujita 


\section{The Crystalline Sponge Method Updated}

Manabu Hoshino, Anupam Khutia, Xing Hongzhu, Yasuhide Inokuma, and Makoto Fujita*

Department of Applied Chemistry, Graduate School of Engineering, The University of Tokyo, and ACCEL (JST), 7-3-1 Hongo, Bunkyo-ku, Tokyo 113-8656, Japan

MH: crystallographer who is in charge of all the crystallographic data

MF: corresponding author (Email: mfujita@appchem.t.u-tokyo.ac.jp)

\section{S1. General X-ray crystallography for the crystalline sponge method}

\section{S1.1. Crystalline nature of the crystalline sponge}

Because of large void spaces in the crystals (ca 50 vol\% for our crystalline sponge crystals), most of MOF compounds contain a lot of solvent molecules that are highly disordered, making crystals extremely fragile and crystallographic analysis considerably difficult. The crystals are severely cracked even if they are taken out from the mother liquor. This property is somewhat similar to that of proteins and, like protein crystallography, it is unavoidable to have some remaining unanalyzable electron density in the pores that are mainly due to disordered solvent molecules. This is a quite common problem in the crystallographic analysis of MOFs and large supramolecular structures.

\section{S1.2. Policy/strategy in the present crystallographic analysis}

Because of the crystalline nature explained above, it is important to clarify policies/strategies on how to solve structures. For the structure refinements of our complexes, the following three policies/strategies were considered:

(1) The use of SQUEEZE: The PLATON SQUEEZE program has been developed to delete unanalyzable electron density in the voids. However, the use of SQUEEZE program may reduce the objectivity of the analysis. Particularly in the determination of absolute structures, when the electron densities of an un-modeled chiral guest is anticipated in the void space, the Flack value after SQUEEZE treatment is not suitable because un-modeled and anticipated chiral molecules is not taken account in calculation of this value. 
(2) The intensive use of restraints and constraints: This is sometimes necessary for deleting all the major alerts in the CheckCif reports. This method, however, also reduces the objectivity of the analysis particularly in the determination of absolute structures. Thus we do not prefer this method. Thus, many CheckCif Alarts, partilucarly alarts at $\mathrm{C}$ level, are only reasoned and not deleted.

(3) The minimum use of restraints: Though a number of alerts remain in the CheckCif reports, the objectivity of the analysis is mostly maintained. We refined the structures based on this policy. What we performed were: (i) minimum use of restraints (actually only a few) on the guest frameworks. (ii) attempt to model cyclohexane molecules (pore solvents) for the uncharacterized pore electron density, where restraints on the solvent frameworks were unavoidable. (iii) reasoning for the CheckCif alerts in the .cifs, text, and SI to carefully address the CheckCif report.

\section{S1.3. Addresses to CheckCif Alerts}

Because of the above policy and the very large unit structures, a large number of Alerts were consequently generated in the CheckCif report. Most of these are not serious and our responses for these are given as follows.

Alert A (short contact between hydrogen atoms): All of the alerts at the level A warned unusual contacts of hydrogen atoms between the cyclohexane solvent and the ligand or among the solvents. This alert can be deleted by DFIX command with a negative target value and small uncertainty. We did not delete this alert because of the policy (3). Also, the geometry of these solvent molecules does not alter the structure of the target guest and never change the conclusion of our paper. This explanation is mentioned in the .cif files using vrf.

Alert B (Hirshfeld difference): The solvent cyclohexane molecule is found in the carbon atoms involved these alerts. This difference is considered as representing collision of them.

Alert B (short contact between hydrogen atoms): This alert is the same as the above alert A. See above.

Alert $C$ : The common reason for all alerts in this level is precision of guest structure. In principle, these alerts will disappear using precise and accurate diffraction data with higher resolution. In any crystallographic analysis, however, the limitation of data resolution surely exists and perfect address to these alerts would be beyond the experimental limitation. We carefully checked these alerts and confirmed that there are no serious failures/misunderstandings. Responses to individual alerts are usually not necessary. 


\section{S1.4. General X-ray Experiments}

All X-ray diffraction data were collected using Rigaku-Oxford Diffraction SuperNova X-ray diffractometer equipped with Atlas S2 CCD detector. Sample crystal was cooled into $100 \mathrm{~K}$ by cold nitrogen stream by Oxford Cryosystems Cobra low temperature system. The $\mathrm{Cu} K \alpha$ radiation from Rigaku-Oxford Diffraction Nova sealed X-ray tube was used for diffraction experiments. Collected data was integrated, corrected, and scaled using the program CrysAlisPro v. 1.171.37.35. Numerical and empirical absorption corrections were performed in this data processing.

All crystal structures were solved by the dual-space iterative method (SHELXT 2014/5) and refined using full-matrix least-squares (SHELXL 2014/7). All non-hydrogen atoms were refined anisotropically. All hydrogen atoms were grown at the geometrically suitable position using the command HFIX in SHELXL and refined isotopically using $U_{\text {iso }}=1.5 U_{\text {eq }}$ (for the methyl group) or $U_{\text {iso }}=1.2 U_{\text {eq }}$ (for the others) of the connected non-hydrogen atom.

In the structural analysis of the crystalline sponge, refinement of cyclohexane molecules were accompanied with considerable difficulties due to their high thermal mobility and overlapping with unsaturated guest molecules by site disorder. Electron density corresponding to cyclohexane molecules in a Fourier map has no atomic resolution in almost all cases. Therefore, some restraints (DFIX, DANG, SIMU, ISOR) were applied for the refinement of them. Their geometry is thus not authentic and should be considered as averaged one in many presumable conformers.

\section{S2. Time-dependent IR measurement for the exchange of the solvent}

As-synthesized 1 was immersed in cyclohexane and the exchange of the pore solvent from nitrobenzene to cyclohexane was monitored by IR measurement.

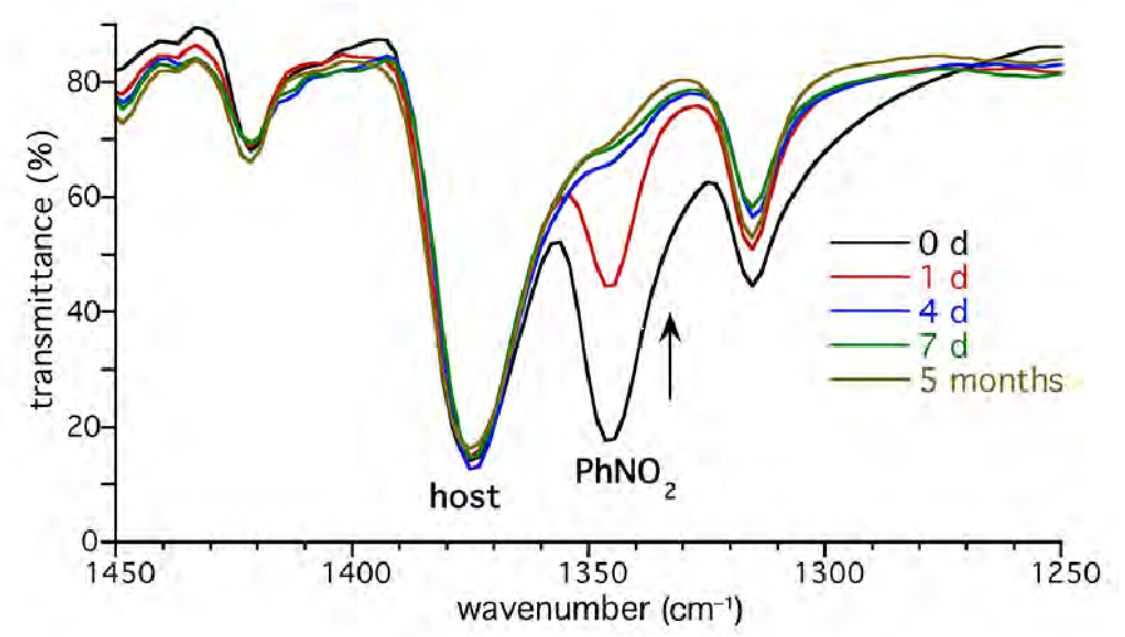

Figure S1 Time-dependent IR measurement for the exchange of the solvent in the pores from nitrobenzene to cyclohexane. 


\section{S3. Preparation of $\left[\left(\mathrm{ZnI}_{2}\right)_{3}(\mathrm{tpt})_{2} \cdot 5.5(\text { cyclohexane })\right]_{\mathrm{n}}(1)$.}

This complex (1, crystalline sponge) was synthesized according to the procedures described previously (Inokuma, Y.; Yoshioka, S.; Ariyoshi, J.; Arai, T.; Fujita, M. Nat. Protoc. 2014, 9, 246252).

Crystallographic data: $\mathrm{C}_{66} \mathrm{H}_{84} \mathrm{I}_{6} \mathrm{~N}_{12} \mathrm{Zn}_{3}, \mathrm{M}_{\mathrm{r}}=2002.96$, crystal dimensions $0.23 \times 0.11 \times 0.05 \mathrm{~mm}^{3}$, Monoclinic, space group, $C 2 / c, a=34.3760(7) \AA, b=15.0832(3) \AA, c=29.6413(9) \AA, \quad \beta=$ 100.675(2) $)^{\circ}, V=15103.0(6) \AA^{3}, T=100(2) \mathrm{K}, Z=8, \rho_{\text {calcd }}=1.762 \mathrm{~g} \mathrm{~cm}^{-3}, 13448$ unique reflections out of 82446 with $I>2 \sigma(I), 968$ parameters, $R_{\text {int }}=0.0574$, final $R$ factors $R_{1}=0.0547$ and $\mathrm{w} R_{2}=$ 0.1588 for all data, $\mathrm{GoF}=1.053$. CCDC deposit number 1418972 .

(a)

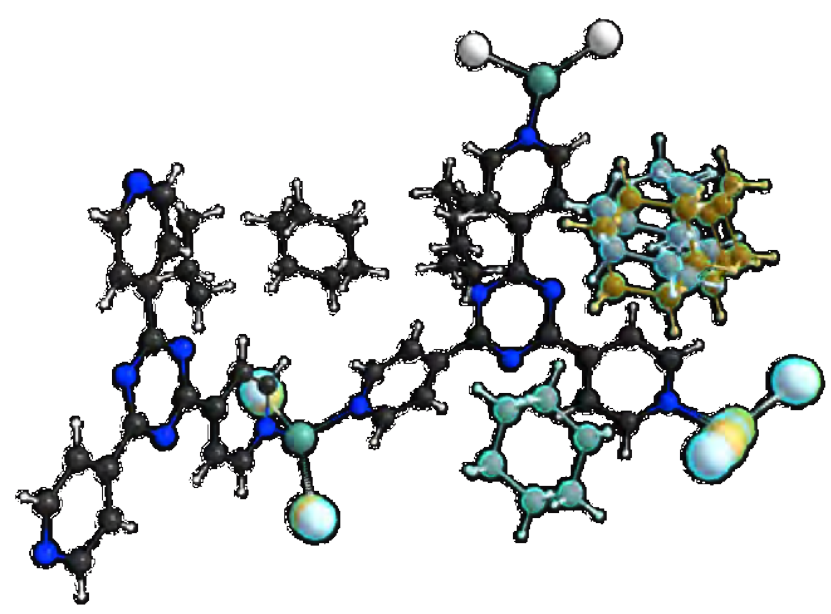

(b)

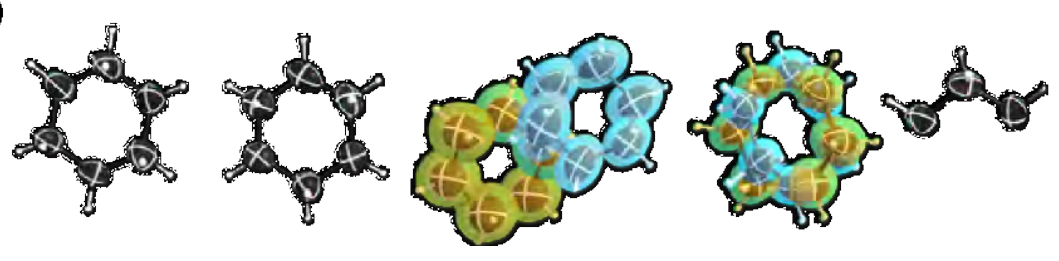

Figure S2 ORTEP drawings (30\% probability) for (a) the asymmetric unit of $\mathbf{1}$ and (b) only guest molecules.

S4. Observed electron density (Fo) maps vs. guest concentration in the crystal. 
(a)

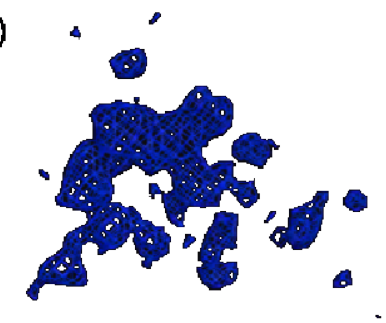

(b)

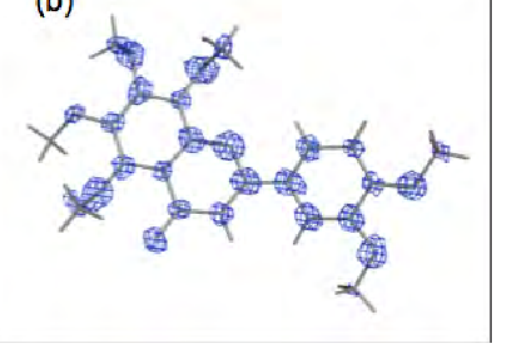

(c)

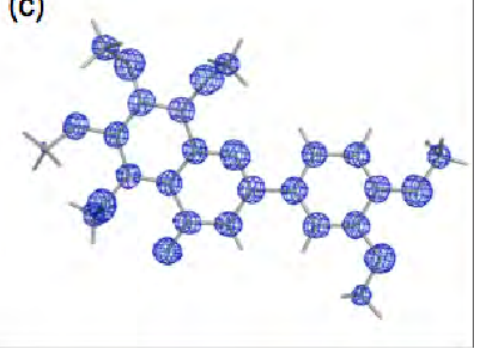

Figure S3 Observed electron density $(F \mathrm{o})$ maps for nobiletin $\mathbf{5}$ obtained under different soaking conditions: (a) guest $5 \mu \mathrm{g}$ in 1,2-dichloroethane/cyclohexane $(5 \mu \mathrm{L} / 45 \mu \mathrm{L})$, solvent evaporation at 50 ${ }^{\circ} \mathrm{C}$ over $3 \mathrm{~d}$, (b) the solvent was slowly evaporated over $7 \mathrm{~d}$ under the same conditions as (a), and (c) the guest amount was increased to $1 \mathrm{mg}$ under the same conditions as (b). The Fo maps are drawn at $0.2,0.6$, and $1.0 \sigma$ level for (a), (b), and (c), respectively.

\section{S5. A general procedure for the preparation of guest-included crystalline sponge}

A rod-shaped single crystal of crystalline sponge 1 (typically, $\sim 200 \mathrm{x} 80 \mathrm{x} 80 \mu \mathrm{m}$ ) is placed in a small vial with a cyclohexane solution $(50 \mu \mathrm{L})$ of a guest $(5 \sim 10 \mu \mathrm{g})$. When the guest is insoluble in cyclohexane, minimum amount of dichloromethane or 1,2-dichloroethane $(\sim 5 \mu \mathrm{L})$ is added. At the lid of the vial is equipped a syringe needle for vapor outlet. A guest-included crystalline sponge is prepared in this vial by slow solvent evaporation (typically, $50{ }^{\circ} \mathrm{C}, 2 \mathrm{~d}$ ). Note that guest amount, kind of solvent, evaporation temperature, and soaking time for completing evaporation need to be optimized based on feedbacks from careful observation of crystals on a microscope, collection of preliminary X-ray diffraction image, and sometimes actual attempt of X-ray crystal structure analysis.

\section{S6. Detailed X-ray crystallography for all the guests}

\section{S6.1. Guaiazulene (3)}

A single crystal of 1 with dimension of $0.19 \times 0.09 \times 0.06 \mathrm{~mm}$ and a solution of guaiazulene $(5 \mu \mathrm{g})$ in $50 \mu 1$ of cyclohexane was prepared for guest soaking. The suitable guest-included crystal for X-ray crystal structure analysis was obtained after the slow evaporation of the solvent for $2 \mathrm{~d}$ at $50{ }^{\circ} \mathrm{C}$. Three independent guest molecules were found in the asymmetric unit of the crystal. The first one was refined as sof $=1$ without restraint and constraint. The second one was site-disordered with cyclohexane molecules. The sof of this guest molecule was estimated as $0.186(6)$ by refinement using a disordered model. The third one was placed on a crystallographic two-fold axis (multiplicity $=2$ ). In addition, symmetrically independent two molecules are disordered at this site. Therefore, the third guest was disordered in four different orientations. The sofs of the two independent disordered parts were estimated as $0.278(10)$ and $0.222(10)$ by refinement using a disordered model. In the refinement 
of the second guest, the use of FLAT, SIMU, and ISOR could not be avoided due to their low occupancies. For the third guest, SIMU was applied for overall molecule and ISOR and DFIX were applied for the bonds and atom that severely overlapped with the symmetrically generated itself. Additionally, geometries of the second and third guests were restrained using SAME in refinement.

Crystallographic data: $\mathrm{C}_{73.50} \mathrm{H}_{78.76} \mathrm{I}_{6} \mathrm{~N}_{12} \mathrm{Zn}_{3}, \mathrm{M}_{\mathrm{r}}=2087.75$, crystal dimensions $0.19 \times 0.09 \times 0.06$ $\mathrm{mm}^{3}$, Monoclinic, space group, $C 2 / c, a=35.0725(6) \AA, b=14.8911(3) \AA, c=30.9658(6), \quad \beta=$ 101.956(2) $)^{\circ}, V=15821.6(5) \AA^{3}, T=100(2) \mathrm{K}, Z=8, \rho_{\text {calcd }}=1.753 \mathrm{~g} \mathrm{~cm}^{-3}, 15108$ unique reflections out of 56858 with $I>2 \sigma(I), 1257$ parameters, final $R$ factors: $R_{\text {int }}=0.0279, R_{1}=0.0379$ and $\mathrm{w} R_{2}=$ 0.1035 for all data, GoF $=1.056$. CCDC deposit number 1418974 .

(a)

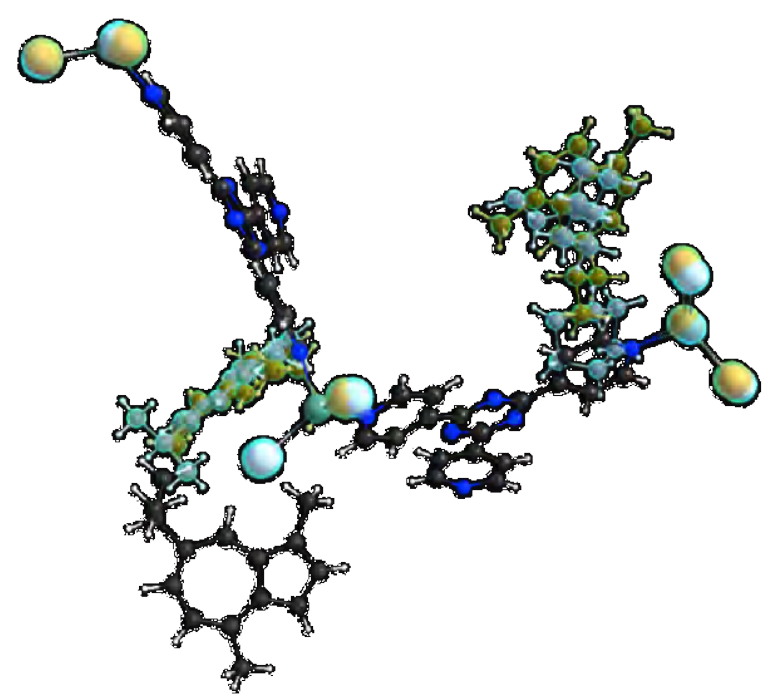

(b)
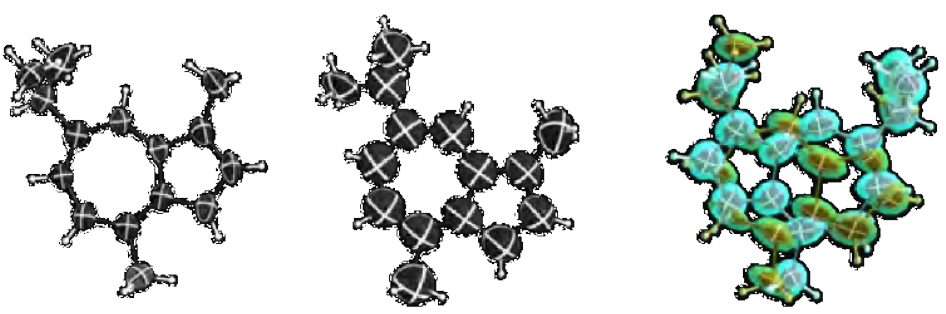

Figure S4 ORTEP drawings (30\% probability) for (a) the asymmetric unit of the guest-included 1 and (b) only guest molecules (3). 
Table S1 A benchmark test of the crystalline sponge method with guaiazulene guest (3).

\begin{tabular}{cccc}
\hline & original reporta & Clardy's report & this report \\
\hline X-ray source & in-house (Mo) & $\begin{array}{c}\text { synchrotron } \\
\text { (ChemMatCARS sector 15) }\end{array}$ & in-house $(\mathrm{Cu})$ \\
$R($ int $)$ & 0.0424 & 0.0546 & $\mathbf{0 . 0 2 7 9}$ \\
$\begin{array}{c}R \text { factor } \\
{\left[F^{2}>2 \sigma\left(F^{2}\right)\right]} \\
\begin{array}{c}\text { SQUEEZE } \\
\text { experimental } \\
\text { conditions }\end{array}\end{array}$ & 0.0859 & 0.0852 & $\mathbf{0 . 0 3 7 5}$ \\
\hline
\end{tabular}

a: Our original report (Inokuma et al., 2013). b: Clardy's report (Ramadhar et al., 2015)

\section{S6.2. Santonin (4).}

A single crystal of 1 with dimension of $0.16 \times 0.10 \times 0.06 \mathrm{~mm}$ was immersed in a solution of santonin $(125 \mu \mathrm{g})$ in $50 \mu \mathrm{L}$ of cyclohexane/dichloromethane $(\mathrm{v} / \mathrm{v}=9: 1)$ in the vial for guest soaking. The pierced vial was allowed to stand at $50^{\circ} \mathrm{C}$ for $1 \mathrm{~d}$ and subsequently at $4{ }^{\circ} \mathrm{C}$ for $1 \mathrm{~d}$.

The soaking conditions were optimized by examining many different conditions. In the optimization process for the inclusion of this guest into the crystalline sponge, superlattice reflections were often observed, which suggested the quadruple periodicity of the $b$ axis (Fig. S6). Direction of the $b$ axis corresponds to a pore of the crystalline sponge. These superlattice reflections suggest that unsaturated guest molecules fill the pore with a periodicity longer than framework. We faced this problem when $5-25 \mu \mathrm{g}$ of guest was used for the guest soaking. When $125 \mu \mathrm{g}$ of guest was used in $50 \mu \mathrm{L}$ of cyclohexane/ dichloromethane solution $(\mathrm{v} / \mathrm{v}=9: 1)$; however, this problem was perfectly suppressed.

Space group change to $P 2_{1}$ was indicated from the statistics of collected diffraction data set based on the extinction rule. Five independent guest molecules were found in the asymmetric unit of the crystal. All guest molecules were refined as sof $=1$ without using restraint and constraint. Parameters for evaluating absolute configuration of refined structure are followings: Flack $\chi=$ $-0.005(2)$, Hooft $y=-0.013(1)$, Parsons $z=-0.0071(11)$.

Crystallographic data: $\mathrm{C}_{285} \mathrm{H}_{317} \mathrm{I}_{24} \mathrm{~N}_{48} \mathrm{O}_{15} \mathrm{Zn}_{12}, \mathrm{M}_{\mathrm{r}}=8484.89$, crystal dimensions $0.16 \times 0.10 \times 0.06$ $\mathrm{mm}^{3}$, Monoclinic, space group, $P 2_{1}, \mathrm{a}=32.8072(2) \AA, b=14.9123(1) \AA, \mathrm{c}=34.9062(2), \quad \beta=$ $105.8220(10)^{\circ}, V=16430.19(19) \AA^{3}, T=100(2) \mathrm{K}, Z=2, \rho_{\text {calcd }}=1.715 \mathrm{~g} \mathrm{~cm}^{-3}, 65911$ unique 
reflections out of 270797 with $I>2 \sigma(I), 3582$ parameters, $R_{\text {int }}=0.0421$, final $R$ factors: $R_{1}=0.0312$ and $\mathrm{w} R_{2}=0.0781$ for all data, $\mathrm{GoF}=1.020$. CCDC deposit number 1418979 .

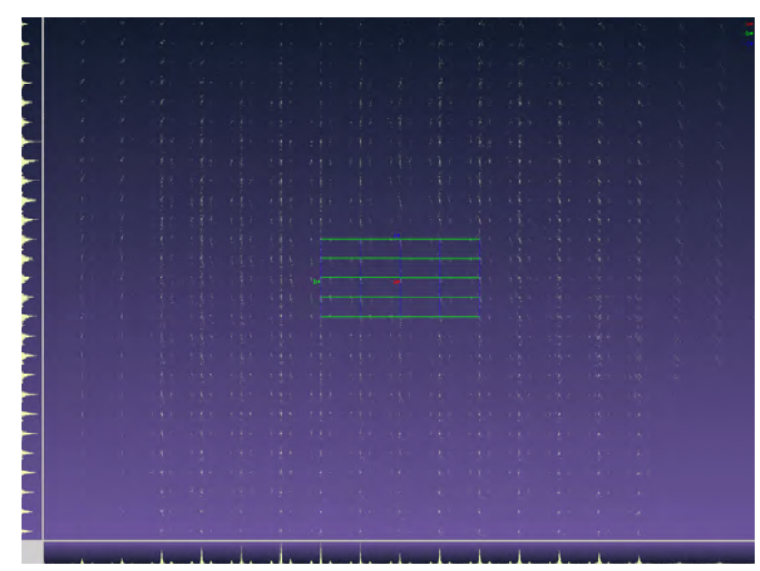

Figure S5 Observation of superlattice reflections along with the $b$ axis by inclusion of santonin molecules in the reciprocal space. The space is described along with the $a^{*}$ axis. Reflections merged into the $b^{*}$ and $c^{*}$ axis are shown in the bottom and left of this space drawing. Small intense of superlattice reflections surrounding with the fundamental reflections along with the $b^{*}$ axis were clearly observed.

(a)

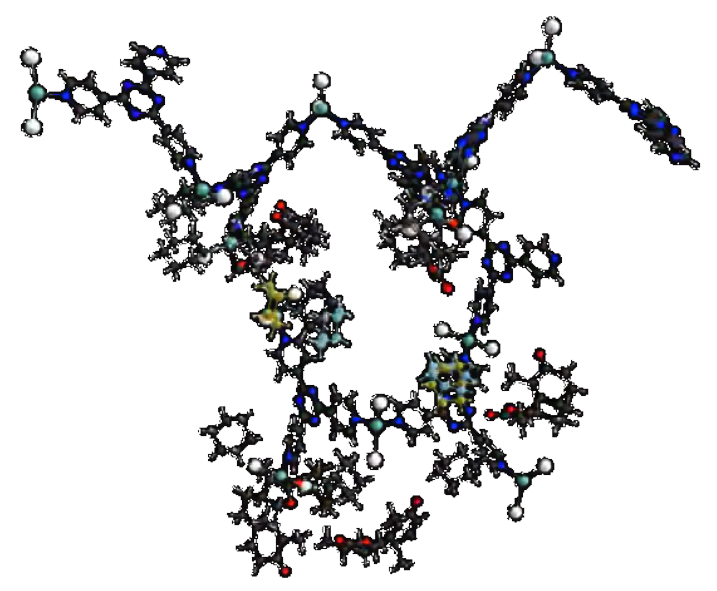

(1)

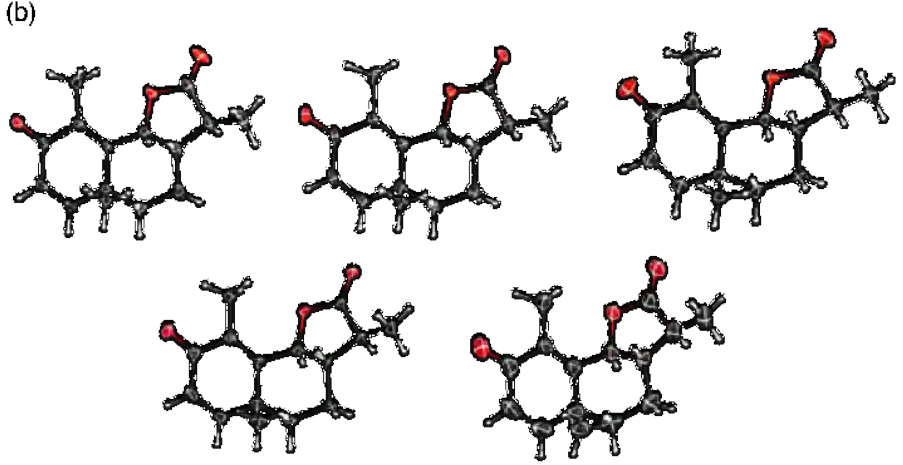

Figure S6 ORTEP drawings (30\% probability) for (a) the asymmetric unit of the guest-included 1 and (b) only guest molecules (4). 


\section{S6.3. Nobiletin (5)}

A single crystal of 1 with dimension of $0.18 \times 0.14 \times 0.07 \mathrm{~mm}$ and a solution of nobiletin $(5 \mu \mathrm{g})$ in 50 $\mu \mathrm{L}$ of cyclohexane/dichloromethane $(\mathrm{v} / \mathrm{v}=9: 1)$ for guest soaking. The pierced vial was allowed to stand at $50{ }^{\circ} \mathrm{C}$ for $1 \mathrm{~d}$ and then at $4{ }^{\circ} \mathrm{C}$ for $1 \mathrm{~d}$. One independent guest molecule was found in the asymmetric unit of the crystal. The sof of this molecule was estimated as $0.508(6)$ by refinement of disorder model with overlapped cyclohexane molecules (refinement of a site disordered model). Restraints of RIGU and DFIX (target value is 1.43(2) $\AA$ ) for one methoxy group were applied in the refinement. The other atoms were refined without using restraint and constraint. To increase occupancy of guest in $\mathbf{1}$, larger amount of guest $(10 \mu \mathrm{g})$ was used for guest soaking with same temperature and soaking time as above. However, at this condition, almost all prepared crystals were severely cracked.

Crystallographic data: $\mathrm{C}_{61.47} \mathrm{H}_{64.79} \mathrm{I}_{6.01} \mathrm{~N}_{12} \mathrm{O}_{4.06} \mathrm{Zn}_{3}, \mathrm{M}_{\mathrm{r}}=1995.85$, crystal dimensions $0.18 \times 0.14 \times$ $0.07 \mathrm{~mm}^{3}$, Monoclinic, space group, $C 2 / c, a=34.4746(8) \AA, b=15.0255(3) \AA, c=30.1535(9), \beta=$ 99.681(2) $)^{\circ}, V=15397.0(7) \AA^{3}, T=100(2) \mathrm{K}, Z=8, \rho_{\text {calcd }}=1.722 \mathrm{~g} \mathrm{~cm}^{-3}, 14374$ unique reflections out of 40991 with $I>2 \sigma(I), 1132$ parameters, $R_{\text {int }}=0.0332$, final $R$ factors: $R_{1}=0.0808$ and $\mathrm{w} R_{2}=0.2136$ for all data, $\mathrm{GoF}=1.197$. CCDC deposit number 1418978 .

(a)

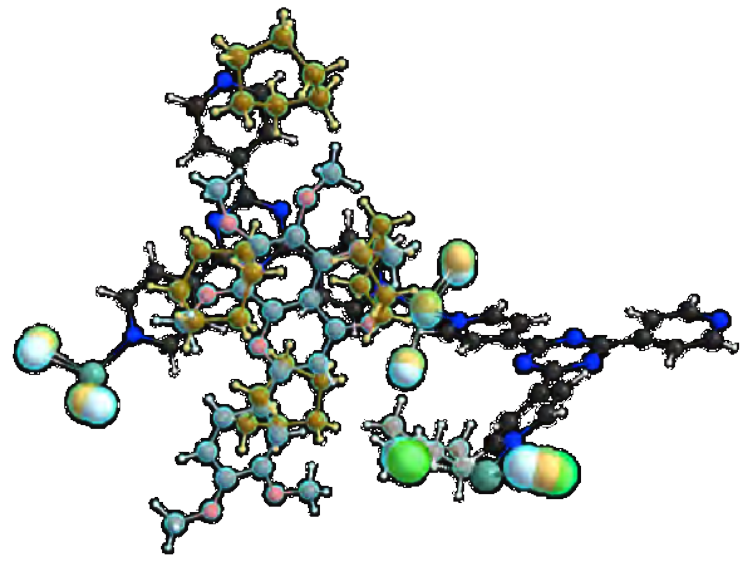

(b)

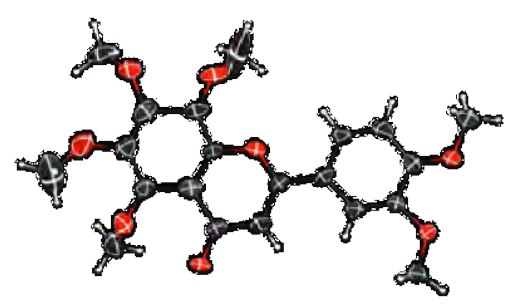

Figure S7 ORTEP drawings (30\% probability) for (a) the asymmetric unit of the guest-included 1 and (b) only guest molecules (5). 


\section{S6.4. Tangeretin (6)}

A single crystal of 1 with dimension of $0.23 \times 0.06 \times 0.05 \mathrm{~mm}$ and a solution of tangeretin $(5 \mu \mathrm{g})$ in $50 \mu \mathrm{L}$ of cyclohexane/dichloromethane $(\mathrm{v} / \mathrm{v}=9: 1)$ for guest soaking. The pierced vial was allowed to stand at $50^{\circ} \mathrm{C}$ for $0.5 \mathrm{~d}$ and then tightly capped (no vapor outlet) at $50^{\circ} \mathrm{C}$ for $2.5 \mathrm{~d}$. After this heating, the vial was left at $4{ }^{\circ} \mathrm{C}$ for $3 \mathrm{~d}$. Some cracks were found in the crystal. The crystal was shaped into $0.10 \times 0.06 \times 0.05 \mathrm{~mm}$ using that cleavage face to prepare a suitable one for X-ray diffraction data collection. In this crystal, two independent guests were found in the asymmetric unit of the crystal. The first one was refined as sof $=1$ and had a disordered chromen fragment with sofs of $0.494(14)$ and 0.506(14), respectively. Geometries of disordered fragments were restrained using SAME in refinement. The methoxy group in the disordered fragment was refined using RIGU. The second one was placed on the inversion center (multiplicity $=2$ ). This independent molecule was refined as sof $=$ 0.5 , meaning $100 \%$ occupancy in this site. Refinement was performed using SADI, SAME, SIMU, and RIGU.

When the guest-soaking was undertaken under the same conditions as for 5 ( $5 \mu \mathrm{g}$ guest in $50 \mu \mathrm{L}$ mixed solvent, at $50{ }^{\circ} \mathrm{C}$ for $1 \mathrm{~d}$ and then at $4{ }^{\circ} \mathrm{C}$ for $1 \mathrm{~d}$ ), obtained crystal structure was isomorphic as the crystal containing nobiletin. The sof of the guest in this isomorphic crystal was 0.67 .

Crystallographic data: $\mathrm{C}_{75} \mathrm{H}_{72} \mathrm{I}_{6} \mathrm{~N}_{12} \mathrm{O}_{10.50} \mathrm{Zn}_{3}, \mathrm{M}_{\mathrm{r}}=2266.95$, crystal dimensions $0.10 \times 0.06 \times 0.05$ $\mathrm{mm}^{3}$, Monoclinic, space group, $C 2 / c, a=34.1414(19) \AA, b=14.5641(5) \AA, c=34.9597(14), \quad \beta=$ $108.633(5)^{\circ}, V=16472.2(13) \AA^{3}, T=100(2) \mathrm{K}, Z=8, \rho_{\text {calcd }}=1.828 \mathrm{~g} \mathrm{~cm}^{-3}, 12761$ unique reflections out of 42914 with $I>2 \sigma(I), 1181$ parameters, $R_{\text {int }}=0.0701$, final $R$ factors: $R_{1}=0.0768$ and $\mathrm{w} R_{2}=$ 0.1730 for all data, GoF $=1.091$. CCDC deposit number 1418980 . 
(a)

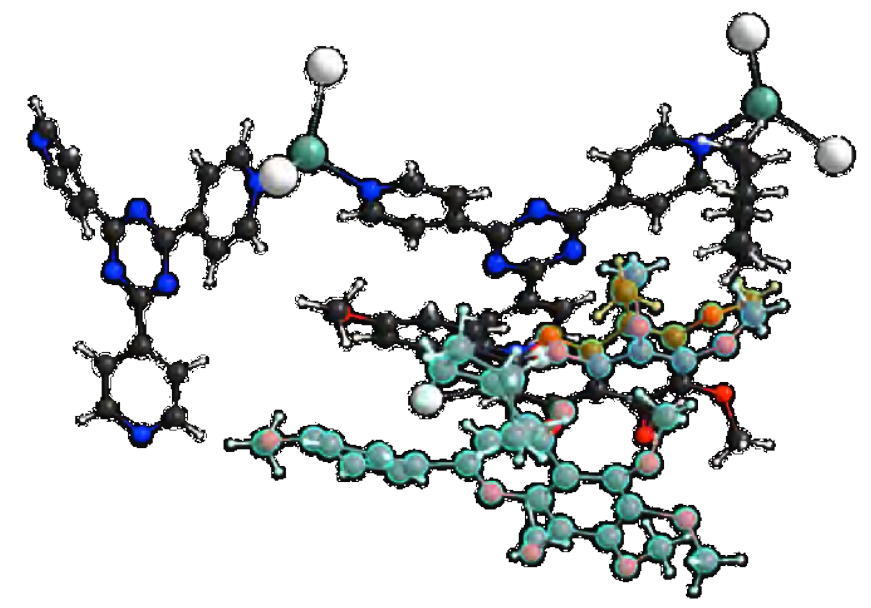

(b)
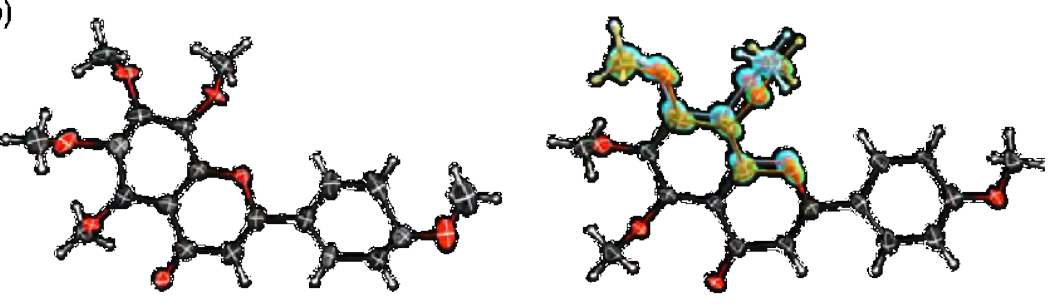

Figure S8 ORTEP drawings (30\% probability) for (a) the asymmetric unit of the guest-included 1 and (b) only guest molecules (6).

\section{S6.5. Heptamethoxyflavone (HMF, 7)}

A single crystal of 1 with dimension of $0.15 \times 0.08 \times 0.06 \mathrm{~mm}$ and a solution of HMF $(5 \mu \mathrm{g})$ in $50 \mu \mathrm{L}$ of cyclohexane/dichloromethane $(\mathrm{v} / \mathrm{v}=9: 1)$ for guest soaking. The pierced vial was allowed to stand at $4{ }^{\circ} \mathrm{C}$ for $1 \mathrm{w}$. When the heated conditions $\left(50{ }^{\circ} \mathrm{C}\right.$ for $2 \mathrm{~d}$ or $50{ }^{\circ} \mathrm{C}$ for $1 \mathrm{~d}$ before $4{ }^{\circ} \mathrm{C}$ for $\left.1 \mathrm{~d}\right)$ were applied for soaking of this guest, prepared crystals were severely cracked. One independent guest molecule was found in the asymmetric unit of the crystal. This molecule was statically disordered into two different alignments with sofs of 0.401(6) and 0.599(6). Many restraints should be applied for refinement of these disordered molecules due to their perfect overlap. Geometries of a flavone (4H-chromen-4-one) skeleton were restrained using SAME (as each other) and SADI (in part). All methoxy-fravone and $\mathrm{C}-\mathrm{O}$ in the methoxy group were restrained using DFIX. The ADPs for both fragments were restrained using SIMU (for all non-hydrogen atoms), ISOR (for one carbon atom), DELU (for two carbon atoms nearby in the rigid group) and RIGU (for five selected methoxy groups).

Crystallographic data: $\mathrm{C}_{67} \mathrm{H}_{66} \mathrm{I}_{6} \mathrm{~N}_{12} \mathrm{O}_{9} \mathrm{Zn}_{3}, \mathrm{M}_{\mathrm{r}}=2140.82$, crystal dimensions $0.15 \times 0.08 \times 0.06 \mathrm{~mm}^{3}$, Monoclinic, space group, $C 2 / \mathrm{c}, a=34.9043(9) \AA, b=14.9550(2) \AA, c=30.3469(8), \beta=100.074(2)^{\circ}$, 
$V=15596.7(6) \AA^{3}, T=100(2) \mathrm{K}, Z=8, \rho_{\text {calcd }}=1.823 \mathrm{~g} \mathrm{~cm}^{-3}, 11507$ unique reflections out of 75828 with $I>2 \sigma(I), 1293$ parameters, $R_{\text {int }}=0.0492$, final $R$ factors: $R_{1}=0.0536$ and $w R_{2}=0.1545$ for all data, $\mathrm{GoF}=1.033$. CCDC deposit number 1418976 .

(a)

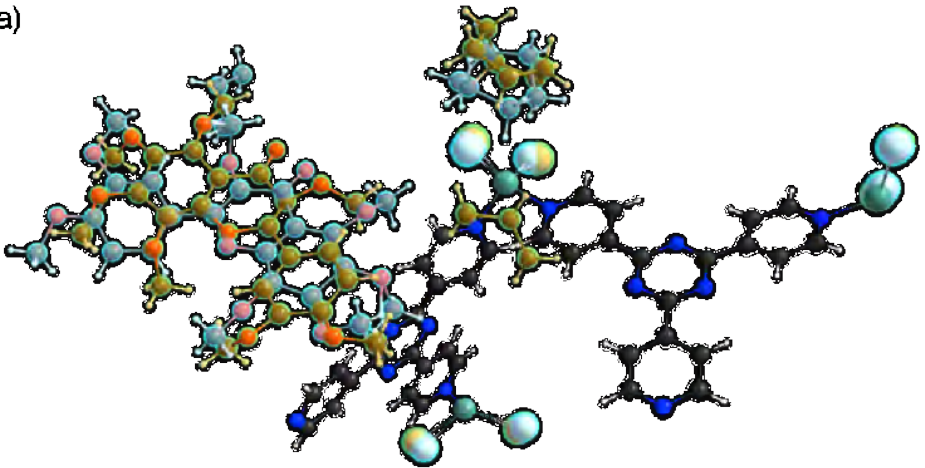

(b)

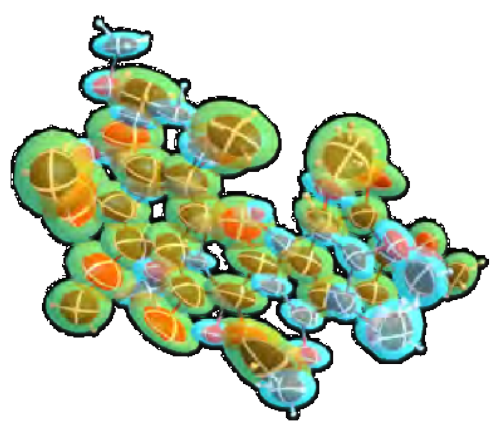

Figure S9 ORTEP drawings (30\% probability) for (a) the asymmetric unit of the guest-included 1 and (b) only guest molecules (7).

\section{S6.6. 2,5-Diisopropylaniline (8)}

A single crystal of 1 with dimension of $0.15 \times 0.09 \times 0.08 \mathrm{~mm}$ was immersed in the solution of 2,5diisopropylaniline $(5 \mu \mathrm{g})$ in $50 \mu \mathrm{L}$ of cyclohexane/dichloromethane $(\mathrm{v} / \mathrm{v}=9: 1)$. The pierced vial was allowed to stand at $50{ }^{\circ} \mathrm{C}$ for $1 \mathrm{~d}$ and subsequently at $4{ }^{\circ} \mathrm{C}$ for $1 \mathrm{~d}$. The crystals were severely cracked when guest soaking was carried out for $2 \mathrm{~d}$ at $50^{\circ} \mathrm{C}$.

Three independent guest molecules were found in the asymmetric unit of the crystal. The first one was found on a general position and refined as sof $=1$ using SIMU. The second one was also placed on a general position. The sof of it was estimated as $0.774(10)$ by refinement of disorder model with 
overlapped cyclohexane molecule. The restraint by SIMU was applied to all non-hydrogen atoms in it. The third one was on the two-fold axis (multiplicity $=2$ ). Its sof was estimated as $0.339(10)$ by the refinement of disorder model with overlapped cyclohexane molecule. Due to this low occupancy, restraints using SAME (as the first one) and SIMU were applied in refinement.

Crystallographic data: $\mathrm{C}_{69.69} \mathrm{H}_{80.80} \mathrm{I}_{6} \mathrm{~N}_{14.11} \mathrm{Zn}_{3}, \mathrm{M}_{\mathrm{r}}=2073.61$, crystal dimensions $0.15 \times 0.09 \times 0.08$ $\mathrm{mm}^{3}$, Monoclinic, space group, $C 2 / c, a=36.8116(10) \AA, b=14.6974(3) \AA, c=30.6993(8), \beta=$ 103.070(2) $)^{\circ}, V=16179.1(7) \AA^{3}, T=100(2) \mathrm{K}, Z=8, \rho_{\text {calcd }}=1.703 \mathrm{~g} \mathrm{~cm}^{-3}, 15236$ unique reflections out of 44068 with $I>2 \sigma(I), 1069$ parameters, $R_{\text {int }}=0.0309$, final $R$ factors: $R_{1}=0.0653$ and $w R_{2}=$ 0.1541 for all data, $\mathrm{GoF}=1.128$. CCDC deposit number 1418973 .

(a)

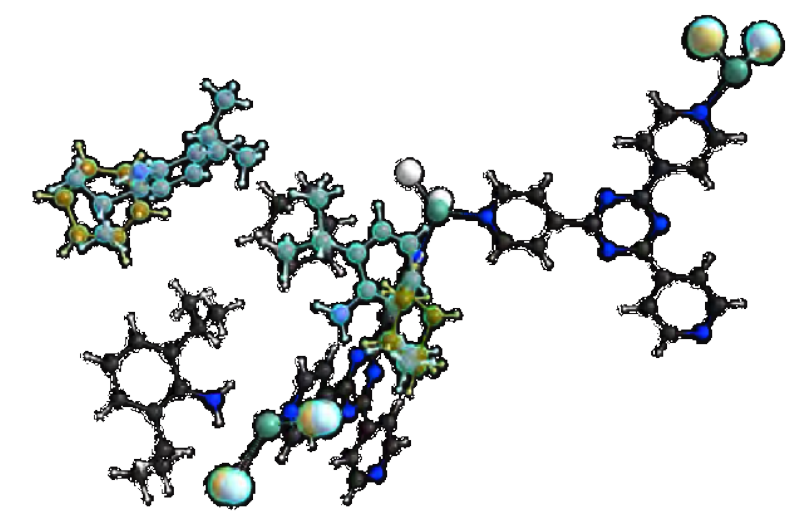

(b)
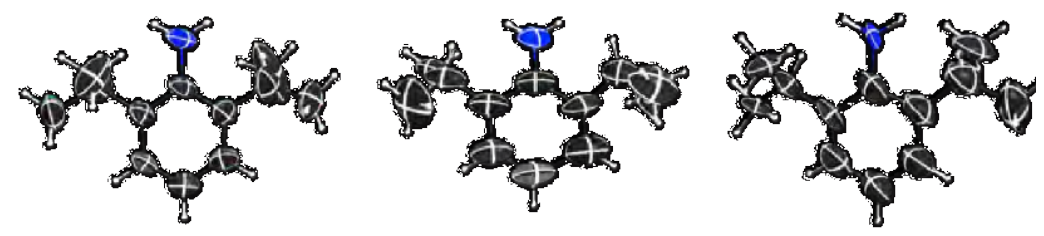

Figure S10 ORTEP drawings (30\% probability) for (a) the asymmetric unit of the guest-included 1 and (b) only guest molecules (8).

\section{S6.7. p-Nitrobenzaldehyde (9)}

A single crystal of 1 with dimension of $0.12 \times 0.11 \times 0.08 \mathrm{~mm}$ was immersed in a solution of $p$ nitrobenzaldehyde $(5 \mu \mathrm{g})$ in $50 \mu \mathrm{L}$ of cyclohexane/dichloromethane $(\mathrm{v} / \mathrm{v}=9: 1)$ for guest soaking. The pierced vial was allowed to stand at $50{ }^{\circ} \mathrm{C}$ for $1 \mathrm{~d}$ and then at $4{ }^{\circ} \mathrm{C}$ for $1 \mathrm{~d}$. This guest also has a tendency to crack the crystal when the crystal was soaked for $2 \mathrm{~d}$ at $50{ }^{\circ} \mathrm{C}$. Soaking at $50{ }^{\circ} \mathrm{C}$ for $1 \mathrm{~d}$ and $4{ }^{\circ} \mathrm{C}$ for additional $1 \mathrm{~d}$ also worked well. Three independent guest molecules were found in the asymmetric unit of this crystal. The first one was placed on a general position and refined as sof $=1$ 
without restraint and constraint. This guest was used as the referenced geometry in SAME for other guests. The second is also places on a general position and disordered with a cyclohexane molecule. The sof of this guest molecule was estimated as 0.704(9). The restraints by SAME, SIMU, and RIGU were applied for refinement of this molecule. The third is placed on a crystallographic two-fold axis (multiplicity $=2$ ) and refined as sof $=0.5$ (the maximum occupancy in this site). The molecule was refined using SAME. Additionally, DFIX with a negative target value was applied for refinement of second and third molecules to avoid collision of them.

Crystallographic data: $\mathrm{C}_{58.32} \mathrm{H}_{48.80} \mathrm{I}_{6} \mathrm{~N}_{14.20} \mathrm{O}_{6.61} \mathrm{Zn}_{3}, M_{r}=2011.88$, crystal dimensions $0.12 \times 0.11 \times$ $0.08 \mathrm{~mm}^{3}$, Monoclinic, space group, $C 2 / c, a=32.5791(8) \AA, b=15.2458(3) \AA, c=29.0346(9), \beta=$ 98.398(2) $)^{\circ}, V=14266.7(6) \AA^{3}, T=100(2) \mathrm{K}, Z=8, \rho_{\text {calcd }}=1.873 \mathrm{~g} \mathrm{~cm}^{-3}, 12144$ unique reflections out of 38259 with $I>2 \sigma(I), 1013$ parameters, $R_{\text {int }}=0.0342$, final $R$ factors $R_{I}=0.0667$ and $w R_{2}=0.2061$ for all data, GoF $=1.090$. CCDC deposit number 1418977 .

(a)

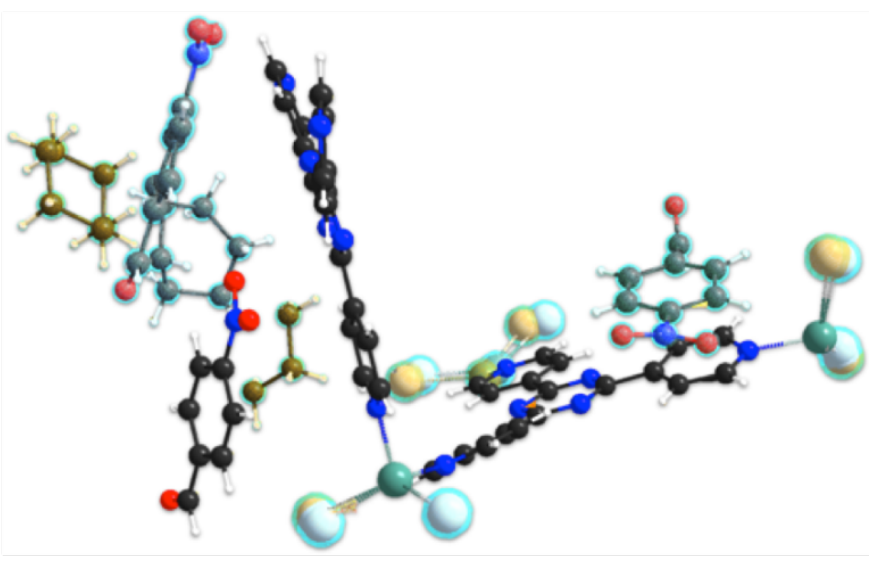

(b)
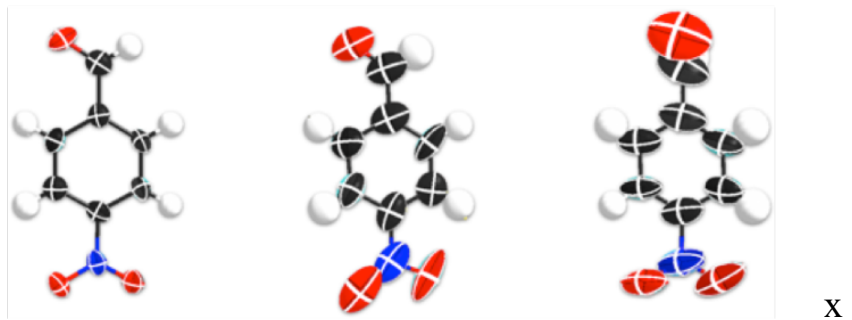

Figure S11 ORTEP drawings (30\% probability) for (a) the asymmetric unit of the guest-included 1 and (b) only guest molecules (9). 


\section{S6.8. Cinnamaldehyde (10)}

A single crystal of 1 with dimension of $0.14 \times 0.11 \times 0.10 \mathrm{~mm}$ was immersed in the solution of cinnamaldehyde $(5 \mu \mathrm{g})$ in $50 \mu \mathrm{L}$ of cyclohexane/dichloromethane $(\mathrm{v} / \mathrm{v}=9: 1)$ for guest soaking. The pierced vial was allowed to stand at $50{ }^{\circ} \mathrm{C}$ for $1 \mathrm{~d}$ and then at $4{ }^{\circ} \mathrm{C}$ for $1 \mathrm{~d}$. Soaking of this guest for 2 $\mathrm{d}$ at $50{ }^{\circ} \mathrm{C}$ clacked the crystal. Two independent guest molecules were found in the asymmetric unit of this crystal. The first one was placed on a general position and refined as sof $=1$. In this molecule, a significant residual electron density peak was found around the terminal. Additionally, the atomic displacement parameters (ADPs) in the formyl oxygen atom were unnaturally expanded compared with the formyl carbon atom. Therefore, that electron density peak was assigned as an oxygen atom and refined as a disordered model representing rotation of this formyl group. To suppress inhomogeneous ADPs in this molecule, the restraints of DELU and SIMU were partially applied. The second one was also placed on a general position and disordered with a cyclohexane molecule. The occupancy of this guest molecule was estimated as 0.477(5). The restraints of SIMU (for the terminal $\mathrm{C}=\mathrm{O}$ part) and SADI (for restraining the carbon atom connecting with the functional group to the ideal geometry as $s p^{2}$ hybridization) were applied.

Crystallographic data: $\mathrm{C}_{64.44} \mathrm{H}_{65.60} \mathrm{I}_{6} \mathrm{~N}_{12} \mathrm{O}_{1.48} \mathrm{Zn}_{3}, \mathrm{M}_{\mathrm{r}}=1989.29$, crystal dimensions $0.14 \times 0.11 \times 0.10$ $\mathrm{mm}^{3}$, Monoclinic, space group, $C 2 / c, a=35.1288(12) \AA, b=14.7670(4) \AA, c=30.8649(11), \beta=$ 101.432(3) $)^{\circ}, V=15693.4(9) \AA^{3}, T=100(2) \mathrm{K}, \mathrm{Z}=8, \rho_{\text {calcd }}=1.684 \mathrm{~g} \mathrm{~cm}^{-3}, 13394$ unique reflections out of 40278 with $I>2 \sigma(I), 1095$ parameters, $R_{\text {int }}=0.0305$, final $R$ factors $R_{1}=0.0416$ and $w R_{2}=$ 0.1216 for all data, GoF $=1.044$. CCDC deposit number 1418970 .

(a)

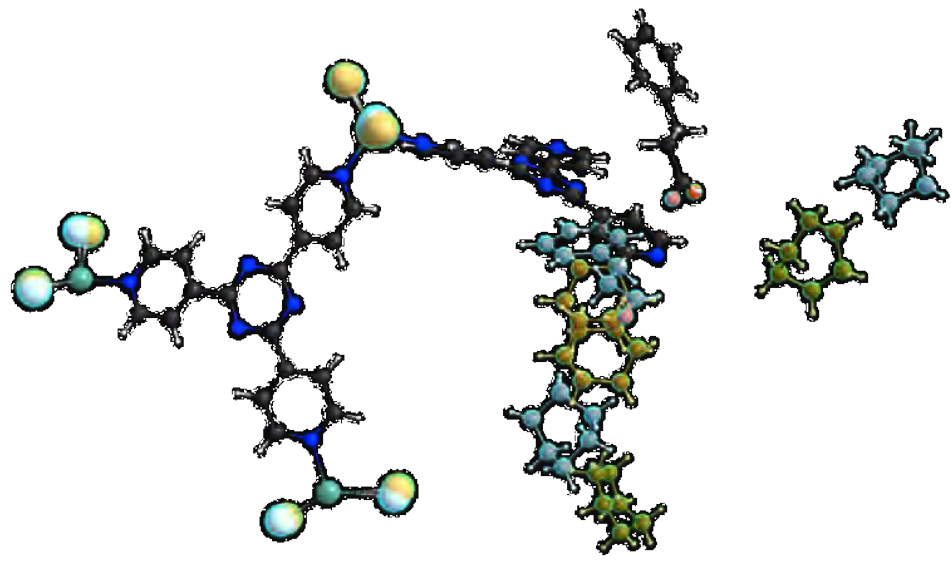

(b)
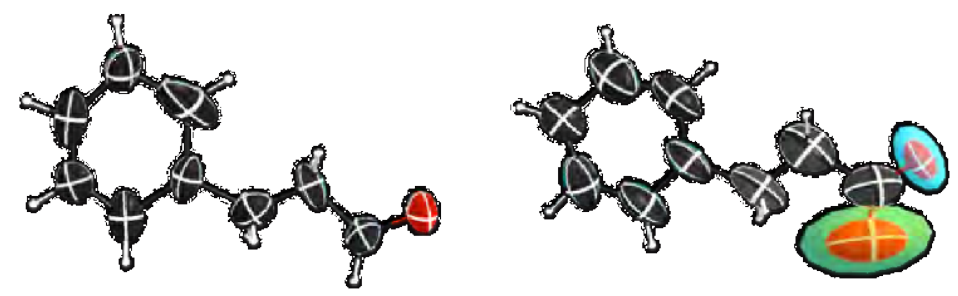
Figure S12 ORTEP drawings (30\% probability) for (a) the asymmetric unit of the guest-included 1 and (b) only guest molecules (10).

\section{S6.9. Dimethyl cubanedicarboxylate (11)}

A single crystal of 1 with dimension of $0.25 \times 0.10 \times 0.08 \mathrm{~mm}$ was immersed in the solution of dimethyl cubanedicaroxyllate $(5 \mu \mathrm{g})$ in $50 \mu \mathrm{L}$ of cyclohexane/dichloromethane $(\mathrm{v} / \mathrm{v}=9: 1)$ for guest soaking. The pierced vial was allowed to stand at $50{ }^{\circ} \mathrm{C}$ for $1 \mathrm{~d}$ and then at $4{ }^{\circ} \mathrm{C}$ for $1 \mathrm{~d}$. The primitive lattice was suggested from statistics of the collected diffraction data set. Sharp and no splitting Bragg spots indicated no cracking in this crystal. Careful observation of the reciprocal space representing the collected data clarified, however, diffuse scattering along with the 010 and 101 directions (Fig. S13).

Figure S13 Diffuse scattering represented in the reciprocal space. The red, green, and blue grids are respectively corresponding to the $a^{*}, b^{*}$, and $c^{*}$ axis. Recorded intensity data of diffraction/scattering are represented using the yellow dots.

Four independent guest molecules were found in the asymmetric unit of this crystal. The first one was placed on a general position and refined as sof $=1$. The restraint of SIMU was applied to one of the two methoxycarbonyl groups. The geometry of this molecule was referred in SAME for refinement of the second and fourth guests. The second one was also placed on a general position. Disorder with a cyclohexane molecule was found in this site. The sof of the guest was estimated as $0.646(17)$ by least-square refinement. The restraints of SIMU (for all non-hydrogen atoms) and 
SAME were applied. The third one was placed on a general position and positionally disordered. The sofs at two different positions were estimated as $0.55(3)$ and $0.45(3)$. The restraints of SIMU (for all non-hydrogen atoms) and SAME (as each other) were applied. The fourth was placed on an inversion center (multiplicity $=2$ ). Due to the requirement from the crystallographic symmetrical operation, this guest molecule was refined as sof $=0.5$. The restraints of SIMU (for all non-hydrogen atoms) and SAME were applied.

Crystallographic data: $\mathrm{C}_{120.90} \mathrm{H}_{108} \mathrm{I}_{11.99} \mathrm{~N}_{24} \mathrm{O}_{12.59} \mathrm{Zn}_{5.99}, \mathrm{M}_{\mathrm{r}}=4012.53$, crystal dimensions $0.25 \times 0.10 \times$ $0.08 \mathrm{~mm}^{3}$, Triclinic, space group, $P \overline{1}, a=14.8292(6) \AA, b=17.9234(7) \AA, c=29.9062(8), \alpha=$ $96.836(3)^{\circ} \beta=93.529(3)^{\circ}, \gamma=110.142(4)^{\circ} V=7364.6(5) \AA^{3}, T=100(2) \mathrm{K}, Z=2, \rho_{\text {calcd }}=1.809 \mathrm{~g} \mathrm{~cm}^{-}$ ${ }^{3}, 20081$ unique reflections out of 57508 with $I>2 \sigma(I), 2083$ parameters, $R_{\text {int }}=0.0605$, final $R$ factors: $R_{1}=0.1296$ and $w R_{2}=0.4390$ for all data, $\mathrm{GoF}=1.574$. CCDC deposit number 1418971 .

(a)

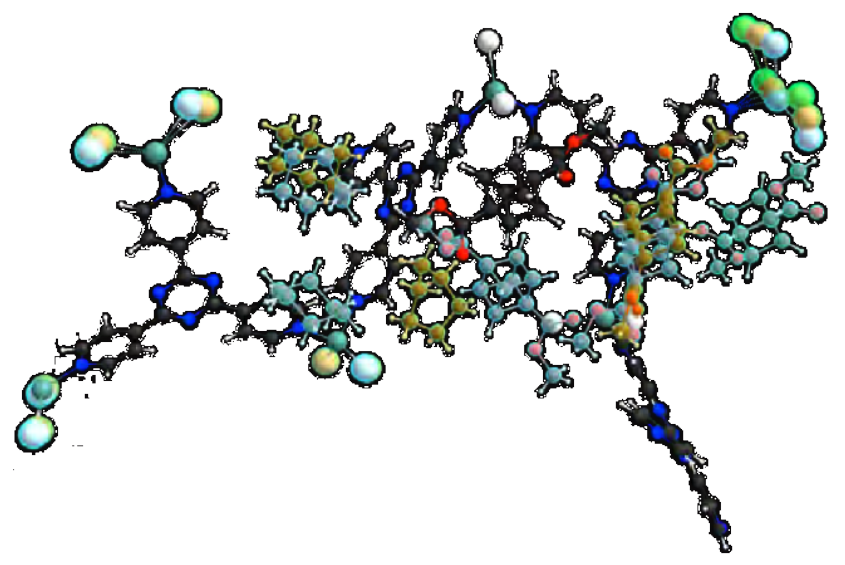

(b)

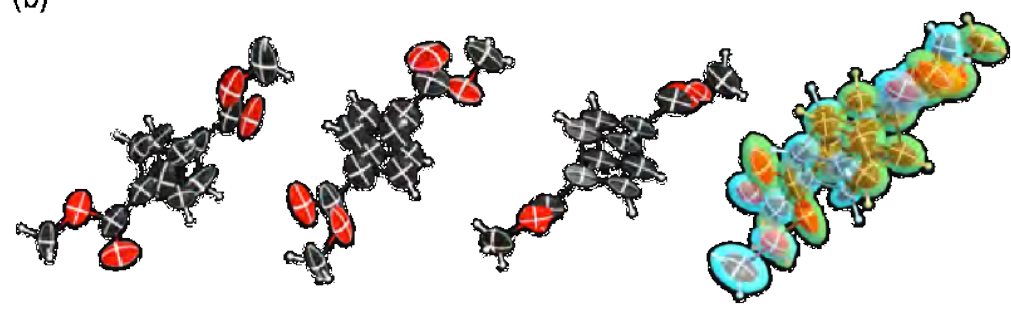

Figure S14 ORTEP drawings (30\% probability) for (a) the asymmetric unit of the guest-included 1 and (b) only guest molecules (11).

By applying treatment as a twinned crystal in data processing, The $R_{1}$ factor of this data was highly improved ( $R_{1}=0.0530$ and 0.0546 for two twining phase). Residual electron densities are well suppressed and some restraints were removed by this treatment. From the viewpoint of crystal structure analysis, treatment as a twinned crystal is recommended to obtain good crystal structure data. However, careful observation to diffuse scattering in the reciprocal space and residual electron 
density before that treatment is important to understand about molecular recognition by the host framework and optimize soaking condition. The CCDC numbers for each phase in the twinned crystal are 1442316 and 1442317. Reconstructed precession image for $\mathbf{1}$ and $\mathbf{1 1}$ are shown in Figure S15.
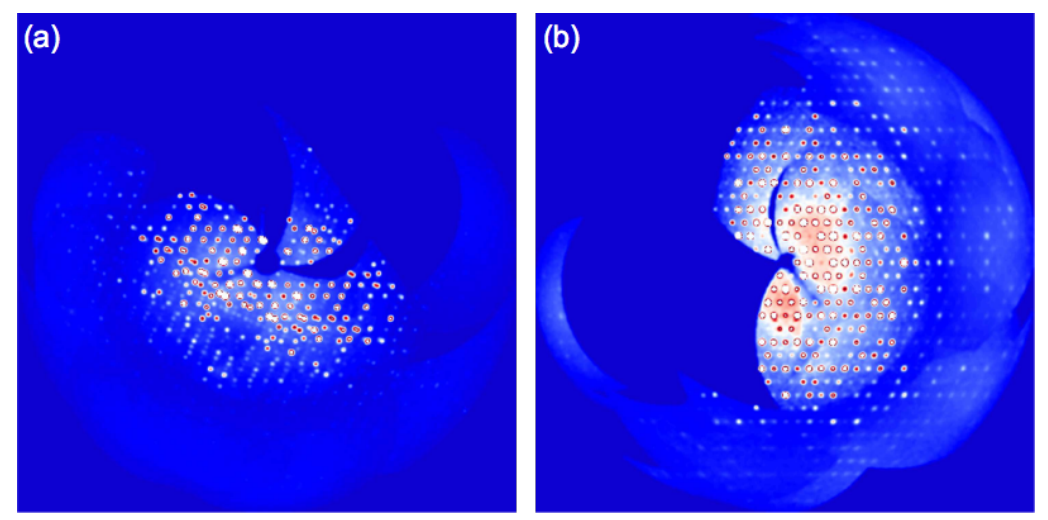

Figure S15. Reconstructed precession image for (a) $\mathbf{1}$ and (b) $\mathbf{1 1}$ in the hk0 plane with $0.8 \AA$ resolution.

\section{S6.10. Bromophenanthrene (12)}

A single crystal of 1 with dimension of $0.28 \times 0.09 \times 0.06 \mathrm{~mm}$ was immersed in a solution of bromophenthrene $(5 \mu \mathrm{g})$ in $50 \mu \mathrm{L}$ of cyclohexane/dichloromethane $(\mathrm{v} / \mathrm{v}=9: 1)$ for guest soaking. The pierced vial was allowed to stand at $50{ }^{\circ} \mathrm{C}$ for $1 \mathrm{~d}$ and then at $4{ }^{\circ} \mathrm{C}$ for $1 \mathrm{~d}$. Four independent guest molecules were found in the asymmetric unit of this crystal. All guest molecules were involved in complex disorder. The first one was placed on the inversion center $($ multiplicity $=2)$ and disordered with a cyclohexane molecule. Its sof was estimated as $0.225(4)$ by least-square refinement. The second one was placed on the two-fold axis (multiplicity $=2$ ) and disordered with a cyclohexane molecule. Its sof was estimated as $0.404(6)$ by least-square refinement. The third and fourth ones formed a dimer at the same site and disordered with cyclohexane molecules. One of the two was positionally disordered into two different orientations with sofs of $0.384(12)$ and $0.281(11)$. The sof of the other guest molecule was estimated as 0.629(7). The occupancies of all guest molecules were not high and a somewhat large number of restraints/constraints had to be applied. The outer benzene rings of the guest were constrained using the AFIX 66 command in SHELXL. Carbon and bromine atoms at the center of the guest molecule were restrained using DFIX and DANG. All non-hydrogen atoms were restrained by SIMU. DELU and ISOR were also applied for selected atoms in guests.

Crystallographic data: $\mathrm{C}_{71.25} \mathrm{H}_{57.96} \mathrm{Br}_{1.92} \mathrm{I}_{6} \mathrm{~N}_{12} \mathrm{Zn}_{3}, \mathrm{M}_{\mathrm{r}}=2193.49$, crystal dimensions $0.28 \times 0.09 \times$ $0.06 \mathrm{~mm}^{3}$, Monoclinic, space group, $C 2 / c, a=35.8691(14) \AA, b=14.8864(3) \AA, c=31.2823(9), \beta=$ 102.711(4) $)^{\circ}, V=16294.2(9) \AA^{3}, T=100(2) \mathrm{K}, Z=8, \rho_{\text {calcd }}=1.788 \mathrm{~g} \mathrm{~cm}^{-3}, 12819$ unique reflections out of 42742 with $I>2 \sigma(I), 1365$ parameters, $R_{\text {int }}=0.0343$, final $R$ factors: $R_{1}=0.0752$ and $w R_{2}=$ 0.2359 for all data, $\mathrm{GoF}=1.038$. CCDC deposit number 1418969 . 
(a)

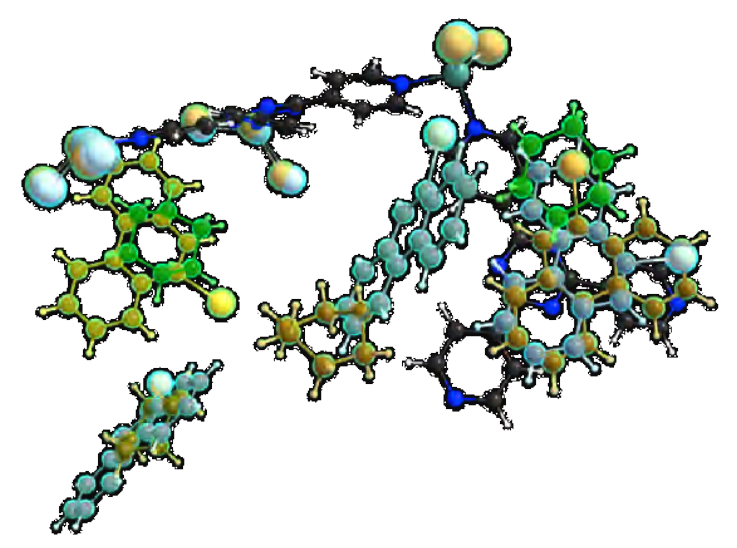

(b)

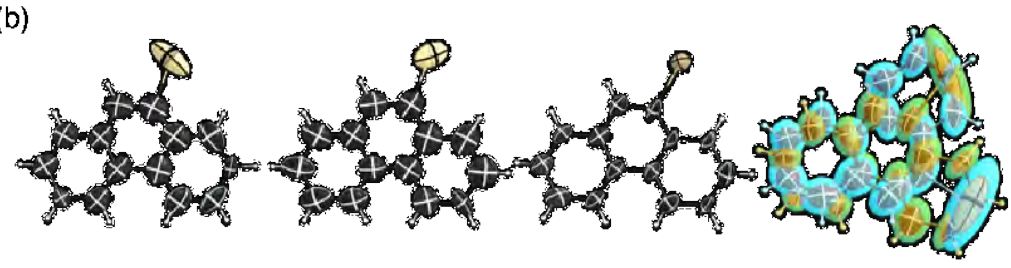

Figure S16 ORTEP drawings (30\% probability) for (a) the asymmetric unit of the guest-included 1 and (b) only guest molecules (12).

\section{S6.11. Vanillin (13)}

A single crystal of 1 with dimension of $0.15 \times 0.14 \times 0.08 \mathrm{~mm}$ was immersed in a solution of vanillin $(5 \mu \mathrm{g})$ in $50 \mu \mathrm{L}$ of cyclohexane/dichloromethane $(\mathrm{v} / \mathrm{v}=9: 1)$ for guest soaking. The pierced vial was allowed to stand at $4{ }^{\circ} \mathrm{C}$ for 1 week. Using the guest-soaking conditions of $50{ }^{\circ} \mathrm{C}$ for $2 \mathrm{~d}$ or $50{ }^{\circ} \mathrm{C}$ for $1 \mathrm{~d}$ and after that left at $4{ }^{\circ} \mathrm{C}$ for $1 \mathrm{~d}$ provided some non-cracked crystals. However, no guest was found in structural analysis. This result implied low guest occupancy in the crystal. Therefore, very slow evaporation $\left(1\right.$ week at $4{ }^{\circ} \mathrm{C}$ ) was applied for soaking of this guest. Some cracking in the crystal was expected because recorded Bragg spots were elongated. The relatively high $R_{\text {int }}$ value represented this non-severe cracking. Four independent guest molecules were found in the asymmetric unit of this crystal. The first one was placed on the two-fold axis (multiplicity $=2$ ) and the sof of this was refined at 0.5 due to the requirement from the crystallographic symmetrical operation. The others were placed on a general position and disordered with cyclohexane molecules. All sofs of them were estimated as $0.487(9)$ by least-square refinement. Two of the three guests formed $\pi$ stacking with the tpt ligand. The ADPs in the guest placed on the top of the $\pi$ stacking were elongated along with the mean plane of the entire non-hydrogen atoms in this guest. This formational feature indicates rotation of this guest molecule in this plane. Some restraint/constraint should be applied in refinement for influence from non-severe cracking. The benzene ring in all guests is constrained using AFIX 66. The restraints using SAME (as other guest molecules), SIMU (for all non-hydrogen atoms), RIGU (partially), DELU (partially), and ISOR (for all non-hydrogen atoms in one of guest molecules) were applied for refinement of this crystal structure. 
Crystallographic data: $\mathrm{C}_{60.92} \mathrm{H}_{58.15} \mathrm{I}_{6} \mathrm{~N}_{12} \mathrm{O}_{5.89} \mathrm{Zn}_{3}, \mathrm{M}_{\mathrm{r}}=2010.11$, crystal dimensions $0.15 \times 0.14 \times$ $0.08 \mathrm{~mm}^{3}$, Monoclinic, space group, $C 2 / c, a=34.0465(14) \AA, b=14.9235(4) \AA, c=30.8377(13), \beta=$ 100.629(4) $)^{\circ}, V=15399.6(10) \AA^{3}, T=100(2) \mathrm{K}, Z=8, \rho_{\text {calcd }}=1.734 \mathrm{~g} \mathrm{~cm}^{-3}, 9952$ unique reflections out of 40997 with $I>2 \sigma(I), 1109$ parameters, $R_{\text {int }}=0.0450$, final $R$ factors: $R_{1}=0.0733$ and $w R_{2}=$ 0.2397 for all data, GoF $=1.038$. CCDC deposit number 1418981 .
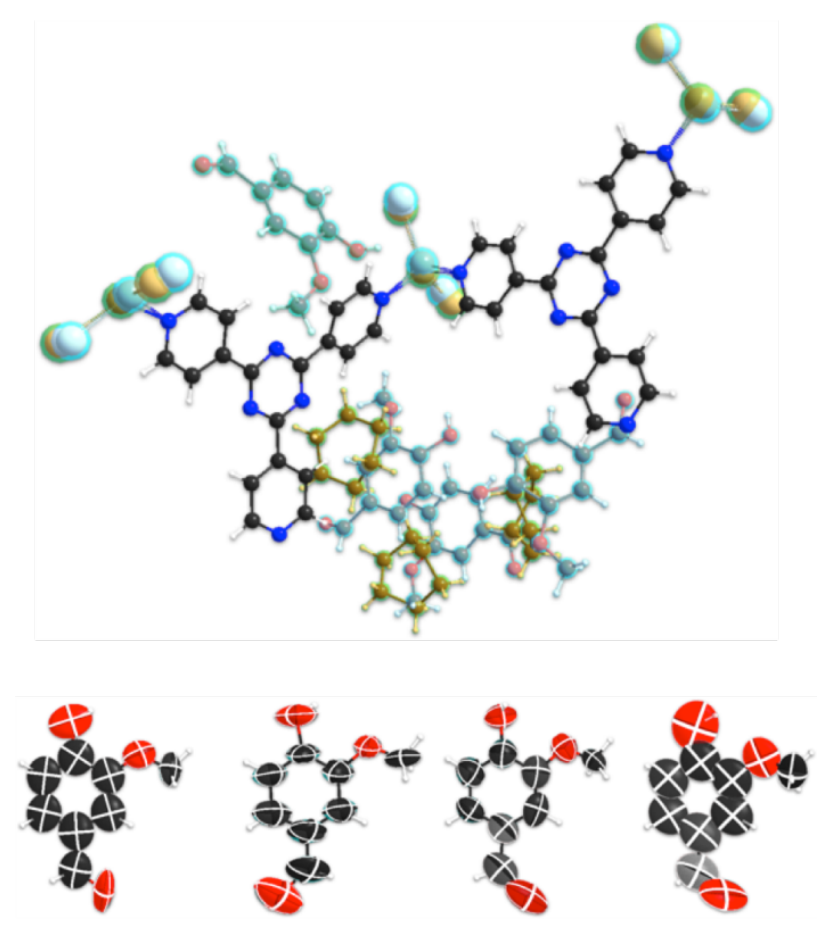

Figure S17 ORTEP drawings (30\% probability) for (a) the asymmetric unit of the guest-included 1 and (b) only guest molecules (13). 